\title{
PODER E HUMOR EM TEMPOS DE PANDEMIA: AS DEEPFAKES DE BRUNNO SARTTORI
}

\section{POWER AND HUMOR IN PANDEMIC TIMES: THE DEEPFAKES OF BRUNNO SARTTORI}

\author{
Cellina Rodrigues Muniz (UFRN) ${ }^{1}$
}

\begin{abstract}
RESUMO
Em que medida o humor pode ser considerado como exercício de poder? Em tempos de pandemia, o que há de revolucionário nesse humor que enseja um riso contra o alto escalão do governo de um país? Essas são questões gerais que abordo neste artigo, tomando como material de análise dois vídeos produzidos/assinados por Brunno Sarttori. O objetivo é ilustrar a tese de humor como prática de resistência a partir do tema da Covid-19, sobretudo a partir de um procedimento clássico no campo discursivo do humor: a paródia.
\end{abstract}

PALAVRAS-CHAVE: Humor; poder; pandemia; Covid-19; Brunno Sarttori.

\section{ABSTRACT}

How can humor be considered as an exercise of power? In times of pandemic, what is revolutionary about this mood that causes a laugh against the high echelon of a country's government? These are general questions that I discuss in this article, taking as analysis material two videos produced/signed by Brunno Sarttori. The objective is to illustrate the thesis of humor as a practice of resistance from the theme of Covid-19, especially from a classical procedure in the discursive field of humor: parody.

KEYWORDS: Humor, power, pandemics, Covid-19, Brunno Sarttori.

\section{INTRODUÇÃO}

Panfletos, libelos, pichações e gritos de ordem talvez possam ser considerados, dentre outros enunciados e/ou textos, como práticas que tomam posição em determinadas relações de poder e assumem, assim, um caráter de resistência. Quando, então, agregam o ingrediente do humor, talvez possam ser considerados com uma pitada a mais de toque revolucionário.

Como afirmou Foucault, "onde há poder, há resistência" (FOUCAULT, 2009, p. 105). E se, como afirmou Bakhtin $(1987,1997)$, o humor pode ensejar um riso carnavalesco que relativiza o mundo, talvez seja possível pensar que a pandemia também possa ser motivo para rir e se rebelar. A paródia - utilizada, por exemplo, nas comédias do dramaturgo grego Aristófanes (447 a.C. - 385 a. C.) - pode ser compreendida, assim, não só como um procedimento clássico de humor (cf. PROPP, 1992), mas também como um meio com o qual é possível "retratar" um mundo em franca descontinuidade e repete essa condição humana nossa de ser, lutar e rir. Isso é o que pretendo mostrar com este artigo.

Tomo como ponto de partida três postulados: a) o poder como prática relacional, móvel, microfísica e difusa, tal como propôs Michel Foucault (FOUCAULT 2007, 2009, 2018); b) o humor como uma forma de ver o mundo em sua alegre relatividade (BAKHTIN, 1987, 1997); c) o humor como linguagem e discurso enquanto regularidade (PROPP, 1992, POSSENTI, 2010, 2018). Partindo, pois, desses princípios, analiso dois vídeos produzidos por Brunno Sarttori. Esses vídeos foram realizados por meio de recursos digitais de Inteligência Artificial (IA) e têm

\footnotetext{
${ }^{1}$ Professora Adjunta do Departamento de Letras e do Programa de Pós-Graduação em Estudos da Linguagem da Universidade Federal do Rio Grande do Norte (DLET/PPgEL-UFRN). E-mail: cellina979164@gmail.com
} 
como mote o Coronavírus. O propósito, assim, é ilustrar, em última instância, a condição ambígua de sermos sujeitos de sujeição e de resistência.

\section{Considerações sobre o humor como campo discursivo}

O humor, além de ser uma condição humana, tem sido objeto de reflexão há séculos, atravessando diferentes momentos históricos (cf. MINOIS, 2003). De modo geral, três grandes perspectivas podem ser ilustradas nessa trajetória de reflexão (cf. PEREIRA, 2017; SKINNER, 2004):

- O humor como rebaixamento (na visão inspirada por obras como Filebos de Platão e Poética de Aristóteles); Cícero);

- O humor como incongruência e efeito de surpresa (o que se vê, por exemplo, em De oratore de

\section{- O humor como defesa psíquica}

E é nessa terceira direção que se pode dizer que o humor é rebelde, como afirmou Freud em seu segundo trabalho voltado para o tema. ${ }^{2}$ Tratava-se de abordar, ali, o humor, como um mecanismo de defesa psíquica (FREUD, 2014 [1927]), isto é, uma forma de autodefesa das dores do mundo e afirmação do princípio do pražer.

Mas, para além de uma abordagem psicanalítica, priorizando um viés mais sociológico e discursivo, pode-se atrelar também o traço de rebeldia ao humor quando se trata de associá-lo a uma cosmovisão carnavalesca em seu exercício de poder.

Como se sabe, trata-se de um conceito formulado por Mikhail Bakhtin (1987) no clássico trabalho $A$ cultura popular na Idade Média e no Renascimento: o contexto de François Rabeleais, em que Bakhtin, por meio da leitura e análise dos textos que compõem Gargântua e Pantagrueß tese de um riso carnavalesco - um riso ambivalente por negar determinados poderes e verdades e afirmar outros, demonstrando a alegre relatividade de tudo. Para isso, como sugeriu Bakhtin (1997, p. 128), a paródia é considerada o recurso por excelência, dada a sua dupla condição de morte (destitui-se o "normal") e de renovação (institui-se o "anormal").

É na articulação entre poder e humor que se pode abordar este último como campo discursivo (cf. MAINGUENEAU, 2010) ${ }^{4}$, tal como propôs Possenti $(2010,2018)$. Considera-se campo discursivo um nicho específico da sociedade marcado por regras e regularidades, cujo funcionamento se faz por conta dos gêneros preferenciais utilizados, dos posicionamentos existentes (ideológicos, estéticos etc.) e das formas institucionais de (forma)ação de seus sujeitos.

O humor, tomado então como campo discursivo, sugere o tratamento de vários elementos, dentre os quais podem ser destacados: assuntos abordados (tipos sociais e profissões, por exemplo), gêneros preferenciais (piadas, charges etc.), estéticas, digamos assim (popular versus erudito), formação e função autoral e posicionamentos (POSSENTI, 2018).

A esse respeito, pensar o humor como campo discursivo implica considerar também tomadas de posição, e que estas nem sempre serão necessariamente revoltosas contra uma ordem dominante: nem sempre os posicionamentos assumidos por meio de um texto/gênero textual

\footnotetext{
2 Sigmund Freud tratou do humor primeiramente em Os chistes e sua relação como o inconsciente (2017 [1905]), em que se detém sobre as técnicas de condensação (duplos sentidos) e deslocamento (desvios de raciocínio) que estariam na base do processo psíquico de produção humorística.

3 Trata-se do conjunto de cinco livros assinados pelo monge francês François Rabelais (1490-1553), inspirados em mitos que envolvem gigantes comilões, beberrões e falastrões. A partir desses livros, Bakhtin (1987) vai se voltar para os ritos, obras e vocabulário próprios de uma cultura popular ainda não controlada pelo Cristianismo nem pelo Estado.

${ }^{4} \mathrm{Na}$ formulação de Maingueneau sobre o que seja um campo discursivo, destaco o seguinte trecho: Um de seus traços é que ele não é homogêneo (...) O campo tem efetivamente um "centro", uma "periferia" e uma "fronteira" (MAINGUENEAU, 2010, p. 51). Uma de suas principais características, assim, é a de sua configuração como espaço conflitual.
} 
humorístico haverão de ser revolucionários. Que o digam, por exemplo, piadas machistas ou racistas, típicas de sociedades tradicionais, conservadoras e intolerantes à diversidade.

Além disso, acrescente-se ainda o fato de que, embora Possenti (2018, p. 29) afirme o caráter não-pragmático do humor (isto é, algo para não ser levado a sério e sem utilidade e/ou efeito maior imediatos), reconhece também o eventual papel que pode vir a assumir em dadas conjunturas (cita, por exemplo, a ação dos humoristas na derrubada da ditadura brasileira).

Assim, partindo da consideração tradicional de Propp (1992) de riso "mau" e riso "bom" (basicamente, rir "contra" versus rir "com", pode-se considerar que os vídeos a seguir, por meio do uso de uma forma de paródia que explora não só semelhanças, mas destaca aspectos negativos (PROPP, 1992, p. 28), apresentam uma tentativa de riso de escárnio a partir de uma cosmovisão carnavalesca de mundo, aliás, de Brasil, tal como propôs Bakhtin em sua análise do contexto cultural do Renascimento a partir da obra de François Rabelais (cf. BAKHTIN, 1987, 1997). Como afirma o autor: "o parodiar é a criação do duplo destronante" (BAKHTIN, 1997, p. 127) em que, em suma, o soberano é negado e reapresentado na figura de bobo para a afirmação de um riso de júbilo nessa grande praça pública da contemporaneidade que é a internet.

\section{Uma análise das deepfakes de Brunno Sarttori}

Brunno Sarttori tem 30 anos e é jornalista, editor de mídias digitais e estudante de Direito. Criador de conteúdo manipulado digitalmente a partir de deepfakee, uma técnica de Inteligência Artificial que sintetiza imagens e/ou vozes humanas combinadas e reformuladas em um vídeo já existente, resultando daí forte efeito de real ${ }^{5}$. Desde o primeiro vídeo produzido em maio de $2019^{6}$ ), Brunno Sarttori seguiu com outras criações e até a data de abril de 2020, época de início da escrita deste artigo, mantém na sua conta de Instagram o número de 367 mil seguidores, o que atesta o significativo impacto, quiçá adesão, dos/aos vídeos de Sarttori no Brasil "pós-verdade" de Bolsonaro ${ }^{7}$.

Neste artigo, como será visto, os vídeos analisados foram produzidos no ano de 2020 e fazem uso de três procedimentos regulares dos textos humorísticos: paródia, condensação e o efeito surpresa ${ }^{8}$. São apresentados dois vídeos que tratam do tema Coronavírus, apresentados em ordem cronológica de divulgação e com uma ligeira contextualização. Ao final de cada qual, uma vinheta encerra a apresentação com a logo/assinatura de Brunno Sarttori em que também se lê "criação, edição e culpa": o que lhe confere, pode-se afirmar, um ethos (ver MAINGUENEAU, 2010) de um enunciador um tanto "atrevido" que não nega e sim assume a sua tomada de posição, com uma imagem de si ainda acrescida de um traço de caráter divertido por conta do uso do som onomatopeico de um quá (a representar possivelmente uma risada).

\footnotetext{
5 As chamadas deepfakes não constituem exatamente um gênero humorístico, haja vista poderem ser utilizadas em textos para além do humor, como no caso de fakenews, textos que visam a um efeito de (supostamente) noticiar uma verdade factual e jornalística. Para possíveis desdobramentos acerca de gêneros humorísticos, ver, por exemplo, a discussão que faz Ramos (2011), em que discute não só a concepção de gêneros discursivos, como atrela a isso casos como piadas, tiras e outros.

${ }^{6}$ Uso da imagem e trechos de fala do então recém-eleito presidente Jair Bolsonaro materializados no personagem humorístico de Chapolin, um desastrado herói criado e interpretado pelo comediante mexicano Roberto Bolaños nos anos de 1970.

7 Para mais detalhes sobre a trajetória de Brunno Sarttori e sua produção como autor de vídeos de animação de humor, ver entrevista com o próprio, em https://gizmodo.uol.com.br/bruno-sartori-cria-deepfakes-bolsonaromoro/ (Acesso em: 1 de mai. de 2020), o que pode suscitar também boas reflexões sobre o humor como campo discursivo a partir especificamente da questão da autoria, tal como sugere Possenti (2018, p. 32).

${ }^{8} \mathrm{O}$ efeito de surpresa é criado a partir do entrechoque entre esquemas distintos de raciocínios, isto é, a quebra entre campos semânticos postos em cena no texto humorístico (esperado versus inesperado, típico versus atípico etc.). A esse respeito, ver Raskin (1985).
} 
Antes, porém, uma rápida retrospectiva de afirmações feitas pelo presidente Jair Bolsonaro em relação à pandemia de Covid-19 (declaradamente contrário às recomendações da Organização Mundial da Saúde e atitude dos governadores em peso, sobretudo quanto ao isolamento horizontal e fechamento do comércio), o que gerou amplas polêmicas na mídia em geral. $\mathrm{O}$ período das declarações, amplamente difundidas pela grande mídia, se inicia a partir do momento de retorno de uma viagem da delegação presidencial dos Estados Unidos, país onde a doença já se manifestava com intensidade, e se caracteriza por um crescente número de casos de infectados e vítimas fatais no país. Cada uma dessas declarações se constitui como um acontecimento discursivo (FOUCAULT, 1995) que irá reverberar em diferentes enunciados (notícias, artigos de opinião, memes etc.):

15/03/2020: "Depois da facada não é uma gripezinha que vai me derrubar não, tá ok?”

22/03/2020: "O povo saberá que foi enganado por esses governadores e por grande parte da mídia nessa questão do Coronavírus."

30/03: "Vai morrer gente, vai..."

28/04 (Ao ser questionado sobre o número de 5.088 mortos até aquela data): "E daí? Lamento. Eu sou Messias, mas não faço milagre."

Eis os vídeos, então, produzidos nesse contexto:

Vídeo 1: Bolsonaro e Ministros cantam "Lava uma Mão" (25 de março de 2020)."

Além da paródia de figuras da cena política, trata-se de uma paródia de letra e melodia da canção de Arnaldo Antunes intitulada "Lavar as mãos", do álbum Castelo Rá Tim Bum, de 1995, voltado para o público infantil. A canção se mostra como uma espécie de manual infantil de higiene (verbos no imperativo, evocação de elementos do universo das crianças em geral, como caixa de areia e mamadeira, além de seu caráter didático). A canção original diz o seguinte:

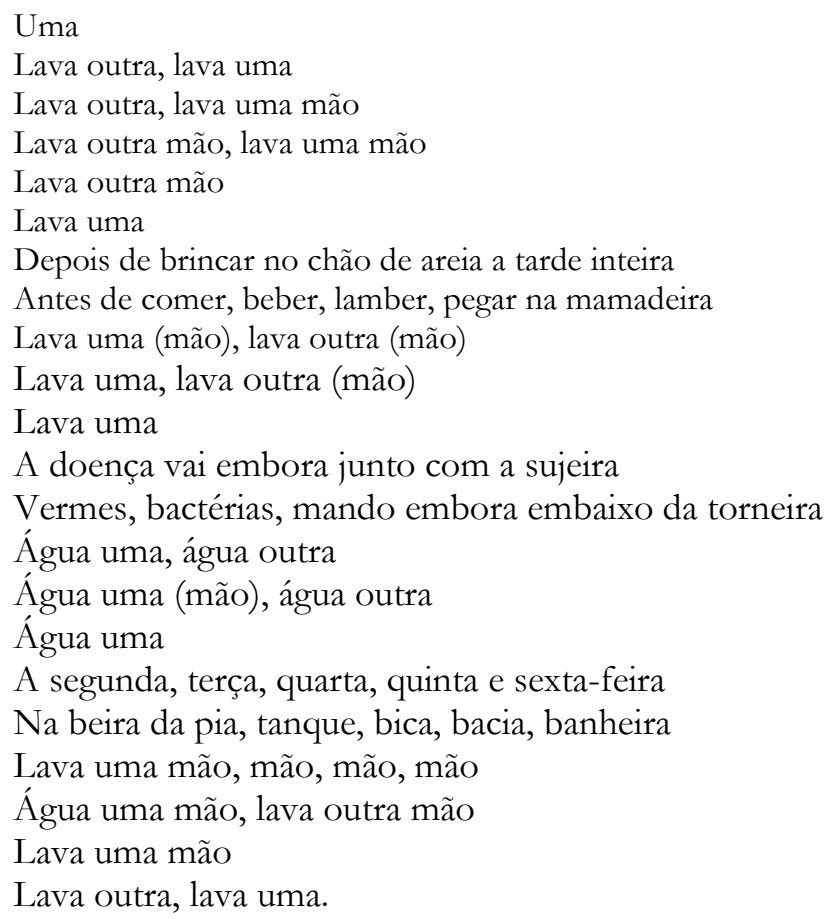

\footnotetext{
${ }^{9}$ Disponível em https://www.youtube.com/watch?v=uPMcf1ceOf4 Acesso em 29 de julho de 2020.
} 
$\mathrm{Na}$ versão parodística de Sarttori, a letra - "cantada" alternadamente por membros do governo como Damares Alves (ministra da Mulher, da Família e dos Direitos Humanos), Abraham Weintraub (então ministro da Educação) e Sergio Moro (então ministro da Justiça e Segurança Pública) e pelo presidente Jair Bolsonaro - diz o seguinte:

Uma

Lava outra, lava uma

Lava outra, lava uma mão

Lava outra mão, lava uma mão

Lava outra mão

Lava uma

Depois de postar que o Corona é besteira

Antes de espalhar no zap

Mais fake da mamadeira

(Refrão)

A doença adora

Uma tia de bobeira

Fique quieta em casa

Não vá dar uma de rolezeira

- Eu sou rolezeira! (Damares)

- Mas tem que ficar em casa, Damares!

Terrivelmente de quarentena

Água uma

Água outra

Água uma

$\mathrm{Na}$ segunda, terça, quarta, quinta e sexta-feira

Lave as mãos com a mesma frequência

Que eu falo besteira

Lava uma...

E também não precisa exagerar,

Senão sua mão cai de tanto esfregar, tá ok?

(BOLSONARO e Ministros cantam "Lava uma Mão", 2020).

Além de explorar uma série de semelhanças junto às figuras políticas (semelhanças faciais, vocais, de sotaque e no uso de expressões corriqueiras, como terrivelmente, tá oke?), essa paródia também explora o "abismo" entre a seriedade das ditas figuras em um quadro de "normalidade" e aquelas que são representadas de modo "infantilizado" e/ou "corrupto" no vídeo. Essa incongruência entre dadas cenografias (MAINGUNEAU, 2015), estratégia tradicional na produção de humor (POSSENTI, 2018), é a grande responsável pelo possível efeito de riso.

Mas o que é de se ressaltar é a série de acontecimentos aos quais o interlocutor é chamado a interpretar, no que se destaca a associação da expressão "uma mão lava a outra", que adquire aí um duplo sentido, procedimento típico também em textos de humor (tal como a quebra entre esquemas de raciocínio, como a descrita acima): mais do que apenas um recurso de higiene pessoal, sugere-se, em relação aos membros do governo de Bolsonaro, duas possibilidades: ou "lavar as mãos", no senso comum algo que seria traduzido como "fingir que não viu" (isto é, se abster, se omitir...); ou a troca de favores (escusos). Seria preciso então considerar, como informação implícita, que Sergio Moro, antes de ser escolhido como ministro de Bolsonaro, foi o maior responsável pela operação Lava-Jato que prendeu o ex-presidente Lula, principal oposição político-partidária de Bolsonaro no contexto eleitoral de 2018.

Vídeo 2: Bolsonaro canta Florentina (Cloroquina) (2 de abril de 2020). ${ }^{10}$

${ }^{10}$ Disponível em https://www.youtube.com/watch?v=Z0eSifdNMBY Acesso em 29 de jul. de 2020. 
Nesse exemplo, a paródia diz respeito a trecho de uma canção do palhaço Tiririca, personagem atrelado à tradição do clássico clown desajeitado e pouco inteligente (mas que depois seria eleito como deputado federal com o slogan "Pior que tá não fica"). A canção original, lançada em álbum homônimo em 1996 tem como refrão o seguinte trecho, fruto da posterior paródia:

Florentina, Florentina,

Florentina de Jesus

Não sei se tu me amas,

Pra que tu me seduz?

No vídeo de Sarttori, há a alusão à defesa dos medicamentos cloroquina e hidroxicloroquina feita por Jair Bolsonaro no combate à Covid-19 em fins de março de 2020, ainda que sem comprovação científica. Nessa paródia, o presidente, subvertido em palhaço, assim se expressa:

\author{
Ei, abestado... No tocante ao tratamento da COVID-19, estamos testando a questão do \\ uso de uma substância, Cloroquina o nome dela... \\ Cloroquina, cloroquina \\ Cloroquina tem no Sus \\ Não sei se funciona \\ Mas a gente deduz! \\ Já tem estudo dizendo que é ineficaz, mas estudo é coisa de esquerdista, tá ok? (risos) \\ (BOLSONARO canta Florentina (Cloroquina), 2020).
}

Em perspectiva bakhtiniana, pode-se dizer que esse vídeo é o que melhor traduz uma visão carnavalesca, ao "transformar" o chefe máximo da Nação, o excelentíssimo presidente Jair Messias Bolsonaro, em um prosaico e leviano palhaço. Esses traços seriam marcados não apenas pela evocação à memória discursiva de palhaços em geral e de quem seja o Tiririca (com suas vestimentas, por exemplo), mas também pela oposição que o presidente faz, no vídeo, aos chamados "estudos científicos", considerados rasamente como "coisa de esquerdista".

Assim, o texto faz não só uso dos procedimentos regulares do humor, tais como a condensação (duplo sentido, expresso via imagética e verbal) e o deslocamento (pela quebra entre as figuras e cenas suscitadas), mas principalmente relativiza a figura política máxima da nação que, supostamente, deveria ser levada a sério e que, aí, não passa de objeto de escárnio, à maneira do que afirmou Bakhtin sobre o riso carnavalesco:

O riso carnavalesco também está dirigido contra o supremo; para a mudança dos poderes e verdades, para a mudança da ordem (...) pertence ao processo propriamente dito de mudança, à própria crise (BAKHTIN, 1997, p. 127).

De que modo, então, o humor ensejado pelos vídeos de Brunno Sarttori pode ser compreendido como exercício de poder?

\title{
3 Considerações sobre poder em Michel Foucault
}

Embora se possa pensar, tal como assinalou Castro (2009, p. 407), que a problemática geral de Michel Foucault tenha sido a problemática do sujeito, é possível dividir, a partir de focos de interesse, métodos de abordagem e estilos de escrita, a obra foucaultiana em três fases distintas (cf. DELEUZE, 2005, GREGOLIN, 2004). Todas essas fases têm em comum pelo menos dois aspectos: a) o postulado da descontinuidade, isto é, a concepção de história não como progressão 
e finalidade, mas como um encadeamento de saltos e rupturas; b) o projeto de desantropologização do homem, ou seja, a consideração do humano não como uma essência, mas sim como constituição histórica a partir de um conjunto de condições de possibilidade. Uma síntese de cada um desses três momentos pode assim ser descrita:

\section{- A fase da arqueologia}

Os primeiros trabalhos de Foucault têm como meta principal investigar a constituição das subjetividades a partir de sistemas de saberes (epistemes). Interessa para ele investigar, por exemplo, como, a partir de camadas históricas descontínuas, o homem foi se objetificando enquanto sujeito, seja um sujeito-objeto em específico (o "louco" das ciências psi (A história da loucura, 1961), seja um sujeito-objeto das ciências humanas em geral (As palavras e as coisas, 1966). É nesta fase que produz $A$ Arqueologia do saber, obra emblemática para os estudos em Análise do Discurso, de 1969, espécie de tratado em que explica seu método de análise dos saberes científicos (a gramática, a economia política, a biologia) enquanto prática discursiva. Interessa, pois, compreender a função enunciativa que determinados sujeitos podem exercer ou não em relação a determinadas formações discursivas, e para isso suspende conceitos e categorias tradicionais de análise, como origem e tradição (um fundo permanente), influência (relação de causalidade), evolução (sucessão de fatos), mentalidade (conjunto de semelhanças), obra e autor.

\section{- $\quad$ A fase da genealogia}

Os modos de subjetivação são ainda o alvo de interesse, mas não mais por meio da ênfase nos saberes que permitem as constituições das subjetividades e sim na relação que têm com o poder em seus diferentes tipos de mecanismos e estratégias. $\mathrm{O}$ foco, pois, está nos dispositivos de poder que assujeitam os sujeitos (hospitais, prisões, escolas, hospícios), seja na ordem do indivíduo e produção de "corpos dóceis" (as técnicas disciplinares), seja na ordem das massas populacionais e políticas de controle da vida (o biopoder). Nessa fase são representativos os livros Vigiar e Punir, de 1975, bem como grande parte de seus cursos no Collége de France.

\section{- $\quad$ A fase das estéticas da existência e das tecnologias de si}

A terceira e última fase do pensamento foucaultiano, representada nos volumes da História da Sexualidade (de 1976 a 1984), vai ter como foco uma ética (um modo de ser e estar no mundo), ou seja, interessa analisar como os indivíduos reconhecem a si mesmos como sujeitos (e, no caso em que se deteve Foucault, sujeitos de uma sexualidade). O seu projeto, expresso nos cursos reunidos no livro $A$ bermenêutica do sujeito, pretendia mapear esse sujeito do desejo, desde a antiguidade clássica (A vontade de saber, 1976) e os primeiros anos da Era Cristã (O uso dos praz̧eres e O cuidado de si, ambos de 1984, além de um quarto volume, publicado postumamente, "As confissões da carne"). Para isso, seria necessário se deter em quatro elementos: a substância ética, os modos de sujeição, as formas de elaboração do trabalho ético e uma teleologia do sujeito moral (moral entendida como regras e valores a ditarem um dever-ser).

Assim, os modos de subjetivação abordados por Foucault foram tratados tanto pelas diferentes formas de sujeição aos saberes-poderes como também pelas práticas de si, em que os indivíduos - numa articulação entre conhecimento e comportamento - são constituídos e constituem-se a si mesmos como sujeitos.

É nessa parte de sua obra que se revela, como em desfecho, a unidade que o próprio Foucault reconhece em seu pensamento a partir do tratamento que quer dar ao que se pode considerar sexualidade. Segundo ele, para se tratar da constituição de uma dada subjetividade (no caso, um sujeito sexual e desejante), há que se levar em conta: "A formação dos saberes que a ela se referem, os sistemas de poder que regulam sua prática e as formas pelas quais os indivíduos podem e devem se reconhecer como sujeitos" (FOUCAULT, 2007, p. 10).

É também nesse momento em que se mostra com intensidade a influência de Nietzsche, sobretudo por conta da relação entre subjetividade e verdade, considerada, em síntese, como um efeito construído a partir de uma conjuntura de forças (ativas e reativas) dos saberes-poderes. Porque, se como afirma Nietzsche "não existem fenômenos morais, apenas interpretações morais 
dos fenômenos" (Nietzsche 1992, p. 73), Foucault vai buscar a razão de ser dessas interpretações do presente não nas indagações conteudistas, mas sim no rastreamento histórico dos enfrentamentos de forças, na "memória dos combates" (Foucault 2008a, p. 171). Como ele próprio afirma:

\begin{abstract}
...se o genealogista tem o cuidado de escutar a história em vez de acreditar na metafísica, o que é que ele aprende? Que atrás das coisas há "algo inteiramente diferente": não seu segredo essencial e sem data, mas o segredo de que elas são sem essência (...)o que se encontra no começo das coisas não é a identidade ainda preservada da origem - é a discórdia entre as coisas (Foucault 2008b, p. 18).
\end{abstract}

O poder, assim, tem caráter vital no pensamento de Foucault, mas para além de uma concepção restrita à segunda fase, em que o poder é encarado sobretudo mais como imposição e assujeitamento. Ao relacionar as deepfakes de Sarttori à concepção de poder em Foucault, enfatizo sua condição de relação e estratégia. Não sendo "coisa" ou "posse" dotada de uma imanência, o poder será encarado como exercício de um sujeito diante de outro/outrem, para o que se pode caracterizá-lo então do seguinte modo:

- Não é coisa que se possua, mas relação que se exerce;

- Não é apenas das grandes ordens jurídicas e econômicas (descendente), mas também das instâncias mínimas e capilares;

- Não é apenas linear, mas difuso;

- Não é apenas repressivo, mas produtivo.

Esses traços, de maneira geral, podem ser expressos na seguinte citação:

o poder não se dá, não se troca nem se retoma, mas se exerce, só existe em ação, como também da afirmação que o poder não é principalmente manutenção e reprodução das relações econômicas, mas acima de tudo uma relação de força (FOUCAULT, 2008, p. 175).

Portanto, e tal como ressalta Castro (2009, p. 326), a pergunta de Foucault não é acerca do que seja o poder, mas sim de como ele funciona. Nessa esteira, para se refletir sobre os vídeos de Sarttori como manifestações de poder em exercício, há que se considerar as seguintes questões:

- Que sistemas de diferenciação ele mobiliza? Pode-se pensar em uma competência técnica e digital de um indivíduo mobilizada contra o chefe supremo do Estado brasileiro, confrontados em posicionamentos políticos distintos, em suma, pró ou anti-Bolsonaro);

- Que objetivos se perseguem? Pode-se propor como alvo imediato o riso de escárnio de uma visão de mundo que inverte o que na normalidade se considera sério e soberano;

- Que modalidades instrumentais são utilizadas? Pode-se pensar nas muitas redes em que tais vídeos são compartilhados e replicados na WEB;

- Que formas de institucionalização estão implicadas? Pode-se atrelar a essa questão todos e quaisquer usos atrelados às redes sociais, canais da plataforma Youtube, enfim, toda a gama implicada na hipercomunicação contemporânea;

- Que tipos de racionalidades estão em jogo? Pode-se arrolar todos os saberes ligados à edição de vídeos e uso da IA (Inteligência Artificial), bem como os ligados ao seu consumo.

A tese que defendo, pois, é que o humor, especificamente os vídeos de Brunno Sarttori que têm como mote a pandemia causada pelo Coronavírus, podem ser avaliados como exercício de humor enquanto prática de resistência em um campo específico, com seus devidos embates - no caso, o político. Isso porque, como ilustrei, os vídeos em questão, utilizando o procedimento clássico da paródia aliado ao recurso da IA, manifestam uma visão carnavalesca de mundo. 


\section{CONCLUSÕES}

Os vídeos abordados neste artigo permitem, em sua leitura e análise, a apresentação de alguns pontos importantes, a saber:

Ao tempo em que o recurso tecnológico da Inteligência Artificial utilizado por Brunno Sarttori demarca, de algum modo, uma descontinuidade no sentido de "limiar, ruptura, corte, mutação, transformação" (FOUCAULT, 1995, p. 6), também são utilizados procedimentos discursivos e linguísticos clássicos e regulares de humor, com destaque para a paródia.

Além do mais, reforça-se a compreensão do humor não só como exercício de poder, mas também como prática de resistência, no sentido atribuído por Foucault. Se o exercício de poder condiz em conduzir condutas (FOUCAULT, 2009, p. 104), em nível micropolítico e em relações móveis e desiguais, e se, no caso dos vídeos, observa-se uma conduta destinada para o rir, e se, sendo o riso ensejado um riso de escárnio, em que o soberano é destituído de sua função "normal" para a função "subterrânea" de tolo, pode-se sim considerar esse caso de humor como um exemplo de confronto entre posicionamentos políticos e de revolta de posições dominadas contra dominantes.

Não à toa, o autor desses vídeos de deepfake, Bruno Sarttori, teria recebido, além de ofensas verbais em seu canal do Youtube e página de Instagram, também ostensivas ameaças ${ }^{11}$, o que parece ser uma retaliação por parte de apoiadores do presidente.

Esse caso, assim, só reafirma o caráter revolucionário que o humor pode assumir, o que já se viu tantas vezes ao longo da História, independentemente da conjuntura atual de pandemia.

\section{REFERÊNCIAS BIBLIOGRÁFICAS}

BAKHTIN, Mikhail. A cultura popular na Idade Média e no Renascimento: o contexto de François Rabelais. São Paulo: Hucitec, 1987.

Problemas da poética de Dostoiévski. Tradução de Paulo Bezerra. Rio de Janeiro: Forense Universitária, 1997.

BOLSONARO canta Florentina (Cloroquina). Direção de Brunno Sarttori. Disponível em https://www.youtube.com/watch?v=Z0eSifdNMBY. Acesso em: 29 de jun. de 2020.

BOLSONARO e Ministros cantam "Lava uma Mão". Direção de Brunno Sarttori. Disponível em https://www.youtube.com/watch?v=uPMcf1ceOf4. Acesso em: 29 de jul. de 2020.

CASTRO, Edgardo. Vocabulário de Foucault: um percurso pelos seus temas, conceitos e autores. Tradução de Ingrid Müller Xavier. Belo Horizonte: Autêntica, 2009.

DELEUZE, Gilles. Foucault. Tradução de Claudia Sant'Anna Martins. São Paulo: Brasiliense, 2005.

FOUCAULT, Michel. A arqueologia do saber. Tradução de Luiz Felipe Baeta Neves. 4 ed. Rio de Janeiro: Forense Universitária, 1995.

Genealogia e poder. In: Microfísica do poder. Organização e tradução de Roberto Machado. 26a. ed. Rio de Janeiro: Edições Graal, 2008.

${ }_{11}$ A esse respeito, ver https://www.youtube.com/watch?v=b qWw-bpYzY. Acesso em: 1 de mai. de 2020. 
- Genealogia e poder. In: Microfísica do poder. Organização e tradução de Roberto Machado. 26a . ed. Rio de Janeiro: Edições Graal, 2008a.

Nietzsche, a genealogia e a história. In: Microfísica do poder. Organização e tradução de Roberto Machado. 26a . ed. Rio de Janeiro: Edições Graal, 2008b.

A hermenêutica do sujeito. Tradução de Márcio Alves da Fonseca e Salma Tannus Muchail. São Paulo: Martins Fontes, 2018.

História da Sexualidade 1: a vontade de saber. 19ª Ed. Tradução de Maria Thereza da Costa Albuquerque e J. A. Guilhon Albuquerque. Rio de Janeiro: Graal, 2009.

A história da sexualidade 2: o uso dos prazeres. Tradução de Maria Thereza da Costa Albuquerque. 12 ed. São Paulo: Graal, 2007.

FREUD, Sigmund. Os chistes e sua relação com o inconsciente. In: Obras completas. Volume 7. Tradução de Fernando Costa Mattos e Paulo César de Souza. São Paulo: Companhia das Letras, 2017 (1905).

O humor. In: Obras completas. Volume 17. Tradução de Paulo César de Souza. São Paulo: Companhia das Letras, 2014 (1927).

GREGOLIN, Maria do Rosário. Foucault e Pêcheux na análise do discurso: diálogos e duelos. São Carlos, SP: ClaraLuz, 2004.

MAINGUENEAU, Dominique. Campo discursivo: a propósito do campo literário. Tradução de Fernanda Mussalin. In: Doze conceitos em Análise do Discurso. São Paulo: Parábola, 2010. 2015.

Discurso e Análise do Discurso. Tradução de Sírio Possenti. São Paulo: Parábola,

MINOIS, George. História do riso e do escárnio. Tradução de Maria Elena O. Ortiz Assumpção. São Paulo: Editora UNESP, 2003.

NIETZSCHE, Friedrich. Além do bem e do mal: prelúdio a uma filosofia do futuro. 1992. Tradução de Paulo César de Souza. São Paulo: Companhia das Letras, 1992.

PEREIRA, Ricardo Araújo. A doença, o sofrimento e a morte entram num bar: uma espécie de manual de escrita humorística. Rio de Janeiro: Tinta da China, 2017.

POSSENTI, Sírio. Humor, língua, discurso. São Paulo: Contexto, 2010.

2018.

Cinco ensaios sobre humor e análise do discurso. São Paulo: Parábola editorial,

PROPP, Vladimir. Comicidade e riso. Vários tradutores. São Paulo: Ática, 1992.

RAMOS, Paulo. Faces do humor: uma aproximação entre piadas e tiras. Campinas, SP: Zarabatana Books, 2011. 
SARTTORI, Brunno. Entrevista. Disponível em em https://gizmodo.uol.com.br/brunosartori-cria-deepfakes-bolsonaro-moro/. Acesso em: 1 de mai. de 2020.

RABELAIS, François. Gargântua e Pantagruel. Tradução de David Jardim Júnior. Belo Horizonte: Itatiaia, 2009.

RASKIN, V. Semantic mechanisms of humor. Dordrecht: D. Riedel, 1985.

SKINNER, Quentin. Hobbes e a teoria clássica do riso. Tradução de Alessandro Zir. São Leopoldo, RS: Unisinos, 2004.

VIDEOMAKER relata ameaças de morte. Disponível em https://youtube.com/watch?v=b qWw-bpYzY. Acesso em: 1 de mai. De 2020. 